\title{
Microstructure and Wear Behavior of Laser-Aided Direct Metal Deposited Co-285 and Co-285 + WC Coatings
}

\begin{abstract}
G.F. SUN, C.S. LIU, L.J. SONG, and J. MAZUMDER
The laser-aided direct metal deposition technique was used to form Co-285 superalloy (A) and Co-285 + 30 wt pct WC (B) wear-resistant coatings on 1018 mild steel. Microstructure, element distribution, phases, microhardness distribution, and wear properties of the two coatings were investigated using scanning electron microscopy (SEM) with energy-dispersive X-ray (EDX) spectrometry, scanning transmission electron microscopy (TEM), X-ray diffractometry (XRD), microhardness testing, and wear testing. Results indicate that both of the coatings had dense structures, as well as a metallurgical bonding with the substrate. In addition, coating B had microcracks and randomly distributed undissolved WC particles in it. Coating A was composed of $\alpha$-Co dendrites, $\mathrm{Co}_{3} \mathrm{~W}$ precipitates, and eutectics, while coating $\mathrm{B}$ was composed of undissolved WC, Co-rich dendrites, eutectics, and the W-rich third phases with various shapes. Crack behavior in coating $\mathrm{B}$ was also discussed. The average microhardness of the matrix in coating $\mathrm{B}$ was $751 \mathrm{HV}_{0.5}$, which was almost 1.8 times that of coating $\mathrm{A}\left(420 \mathrm{HV}_{0.5}\right)$. Wear results indicate that the wear resistance of coating B was improved by 6.8 times compared with that of coating A. The improvement in wear resistance is believed to be partially due to the undissolved WC and the formation of large numbers of carbides in the matrix working as wear-resistant phases and partially due to the good bonding between the hard phases and the tough matrix.
\end{abstract}

DOI: $10.1007 / \mathrm{s} 11661-010-0189-3$

(C) The Minerals, Metals \& Materials Society and ASM International 2010

\section{INTRODUCTION}

RoLLS are the main deformation tools in rolling mills. They withstand very high loads, thermal fatigue, and severe environmental attack. As a result, they often fail due to cracks, spalling, and wear ${ }^{[1,2]}$ Roll materials with long service life are specially required. Cobalt is widely used as a hard facing material in applications requiring good wear resistance, corrosion resistance, and heat resistance, as it combines hardness with ductility. It also demonstrates good corrosion resistance. Many of the properties of these alloys arise from the crystallographic nature of cobalt, the solid solution strengthening effects of chromium, tungsten, and molybdenum, the formation of metal carbides, and the corrosion resistance imparted by chromium, ${ }^{[3,4]}$ among which precipitation hardening is the primary strengthening mechanism. Ceramic materials are often added to metal matrix to form composite coatings to improve the

G.F. SUN, formerly Postdoctoral Candidate, Key Laboratory for Anisotropy and Texture of Materials of Ministry of Education, Northeastern University, and Visiting Scientist, Center for LaserAided Intelligent Manufacturing, University of Michigan, is Instructor, School of Mechanical Engineering, Jiangsu University, Zhenjiang, Jiangsu, 212013, P.R. China. C.S. LIU, Professor, is with the Key Laboratory for Anisotropy and Texture of Materials of Ministry of Education, Northeastern University, Shenyang, Liaoning, 110004, P.R. China. L.J. SONG, Postdoctor, and J. MAZUMDER, Professor, are with the Center for Laser-Aided Intelligent Manufacturing, University of Michigan, Ann Arbor, MI, 48109. Contact e-mail: mazumder@umich.edu

Manuscript submitted April 3, 2009.

Article published online April 14, 2010 wear resistance of the matrix. ${ }^{[5,6]}$ Cobalt is often mixed with WC in composites for promoting wear resistance and high-temperature properties. Literature on the study of $\mathrm{Co}-\mathrm{WC}$ is widely available. ${ }^{[7-10]} \mathrm{Co}-\mathrm{WC}$ hard alloy is widely used as a roll material for its high hardness. However, its poor toughness and high manufacturing cost need to be improved. Composite hard alloy rolls with cast steel as the inner part and hard alloy as the work layer have been a trend in the roll industry.

Laser-aided direct metal deposition is a new rapid manufacturing technology, which is a material-additivebased manufacturing process in which the deposited material has a metallurgical bonding with the substrate. The advantage of this technology is its ability of onestep manufacture, which greatly reduces the lead time and investment costs of mold and die design, the fabrication of hard or rare metal components, the repair of refractory and costly components, etc..$^{[11-17]}$

In view of the preceding information, this study attempted to manufacture the Co-based superalloys + WC coatings (work layer) on mild steel (inner part) by laser-aided direct metal deposition technology and to explore the feasibility of manufacturing hard alloy roll with this method. In this article, Co-285 $+30 \mathrm{wt}$ pet WC coatings (B) were fabricated on the 1018 mild steel substrates. Such composite coatings can offer both enhanced wear resistance with the hardness of the WC and relative toughness of the Co-285 superalloy. In order to differentiate the effect of $\mathrm{WC}$ and determine the optimal WC addition for further investigation, Co-285 coatings (A) as a counterpart were also fabricated. The microstructure, phases, and mechanical properties of the two coatings were analyzed. 


\section{EXPERIMENTAL PROCEDURE}

The system at the University of Michigan includes a $6 \mathrm{~kW}$ RF excited $\mathrm{CO}_{2}$ laser (Trumpf Inc., Plymouth, MI) integrated with a 5-axes workstation controlled by an Allan Bradley 8400 controller (Rockwell Automation, Milwaukee, WI). The substrate material was 1018 mild steel whose chemical composition is listed in Table I. The as-received substrate was cut into samples of dimensions $50 \mathrm{~mm} \times 30 \mathrm{~mm} \times 8 \mathrm{~mm}$. Prior to laser processing, the samples were polished to remove the oxide layer and then cleaned with acetone and deionized water. Atomized Co-285 powders $(-125 \mu \mathrm{m} /+45 \mu \mathrm{m}$, provided by Praxair, with a composition similar to $\mathrm{Co}$ Alloy 31$)$ and WC particles $(-80 /+149$ mesh, provided by Inframat Advanced Materials) in the weight ratio of 70:30 were used as feedstock material. The composition of Co-285 superalloy is listed in Table I. Successive layers were scanned normal to each other, and two tracks have been scanned with an overlap ratio of 50 pct. The step sizes in the $Y$ and $Z$ directions were 0.76 and $0.25 \mathrm{~mm}$, respectively. The deposited coatings had an area of $25 \mathrm{~mm} \times 25 \mathrm{~mm}$ in the $X-Y$ plane. The laser beam with a Gaussian mode is $0.5 \mathrm{~mm}$ in diameter. Powder was delivered with a concentric nozzle in which beam and powder come through the same nozzle. The concentric nozzle design offers equal deposition rates in any direction. Inert gas blown through the nozzle helps both in powder delivery and shielding the deposit from oxidation. The pressures of the delivering and shielding gas helium were 28 and 25 PSI, respectively. Processing parameters for coating $\mathrm{A}$ and $\mathrm{B}$ were as follows: laser power $0.8 \mathrm{~kW}$, powder flow rate $8.6 \mathrm{~g} / \mathrm{min}$, and scanning speed $0.375 \mathrm{~m} / \mathrm{min}$ and laser power $1 \mathrm{~kW}$, powder flow rate $8.5 \mathrm{~g} / \mathrm{min}$, and scanning speed $0.3 \mathrm{~m} / \mathrm{min}$. Coatings $\mathrm{A}$ and $\mathrm{B}$ were scanned for six and two layers, respectively.

After laser treatment, the specimens were sectioned, mounted, ground, polished, and etched with an etchant $\left(65\right.$ pct $\mathrm{HNO}_{3}: 32$ pct $\left.\mathrm{HCl}=1: 3\right)$ for scanning electron microscopy (SEM, PHILIPS* XL30FEG) with energy-

*PHILIPS is a trademark of FEI Company, Hillsboro, OR.

dispersive X-ray (EDX) analysis. The phases present in coatings $\mathrm{A}$ and $\mathrm{B}$ were identified using X-ray diffractometry (XRD, Rigaku rotating Anode XRD) with $\mathrm{Cu}$ $K_{\alpha}$ generated at $20 \mathrm{kV}$ and $100 \mathrm{~mA}$ and a scanning speed of $2 \mathrm{deg} / \mathrm{min}$. An analytical scanning transmission electron microscope (STEM, JEOL** 2010F) was used

**JEOL is a trademark of Japan Electron Optics Ltd., Tokyo. to analyze the microstructure and to determine the phases in coating A. After mechanical and chemical polishing to a thickness of $0.08 \mathrm{~mm}$, discs with a diameter of $3 \mathrm{~mm}$ were punched from the coating region. Specimens for the transmission electron microscopy (TEM) examination were prepared by a twin-jetpolishing technique in a solution of $90 \mathrm{vol}$ pct ethanol and $10 \mathrm{vol}$ pet perchloric acid at $40 \mathrm{~V}$ and $243 \mathrm{~K}$ $\left(-30{ }^{\circ} \mathrm{C}\right)$. Microhardness of the cross section from the coating surface to the substrate was measured using a Clark CM-400 AT microhardness tester at a load of $500 \mathrm{~g}$ and a loading time of 10 seconds. Indentations on the undissolved WC were avoided. Sliding wear tests were conducted with a ball-on-disk apparatus (Microphotonics, Tribometer TRBH, MT/60/NI) under dry sliding conditions at room temperature. The disks were made using the coating samples with the dimensions of $20 \mathrm{~mm} \times 20 \mathrm{~mm} \times 8 \mathrm{~mm}$. Their surfaces were ground and polished with 2000 grit paper. The applied load was $20 \mathrm{~N}$. A fixed rotating speed of $7000 \mathrm{~mm} / \mathrm{min}$ was used. Every test lasted for 60 minutes (sliding distance $420 \mathrm{~m}$ ). Wear groove areas were measured with a Surfcom 130A profilometer every 10 minutes after beginning the test. A ruby ball (1570-1800HV) with a diameter of $3 \mathrm{~mm}$ was used as the counter-body. The ball was dressed prior to each test to remove any debris from previous tests and to ensure reproducibility in the test conditions. The average values of the volume losses from coatings A and B were compared ( $>3$ measurements of each wear groove). The microstructure of the deposited coatings after the ball-on-disk wear test was observed with SEM and the wear mechanism was explained.

\section{RESULTS AND DISCUSSION}

\section{A. Microstructure and Phases}

Coating A was composed of dendrites and the eutectics, as shown in Figure 1(a). The area fraction of the dendrites was about 73 pct, analyzed using one function of the Adobe Photoshop image software. Furthermore, some tetragonal precipitates formed in the dendrites (indicated by the arrows in Figure 1(a)). Figure 1(b) represents the grain structure of the cross section of the interface between consecutive layers, which is marked by the change of dendrite arm spacing and by a transient region (indicated by the white arrows). Furthermore, some micropores can be detected near the transient region. Figure 1(c) (lower part) shows the magnified microstructure of the interface. An equiaxed microstructure is the preferred one at the interface, which is different from the case in Majumder's investigation. ${ }^{[18]}$ It is evident that some remelting of the underlying layer has occurred. The crystallographic

Table I. Chemical Composition of 1018 Mild Steel and Co-285 (Weight Percent)

\begin{tabular}{lccccccccc}
\hline Element & $\mathrm{Fe}$ & $\mathrm{C}$ & $\mathrm{Mn}$ & $\mathrm{P}$ & $\mathrm{S}$ & $\mathrm{Cr}$ & $\mathrm{W}$ & $\mathrm{Ni}$ & $\mathrm{Co}$ \\
\hline Substrate & 98.81 to 99.26 & 0.18 & 0.6 to 0.9 & $0.04 \max$ & $0.05 \max$ & 0 & 0 & 0 & 0 \\
Co-285 & 0 & 0.5 & 0 & 0 & 0 & 26 & 8 & 11 & bal \\
\hline
\end{tabular}



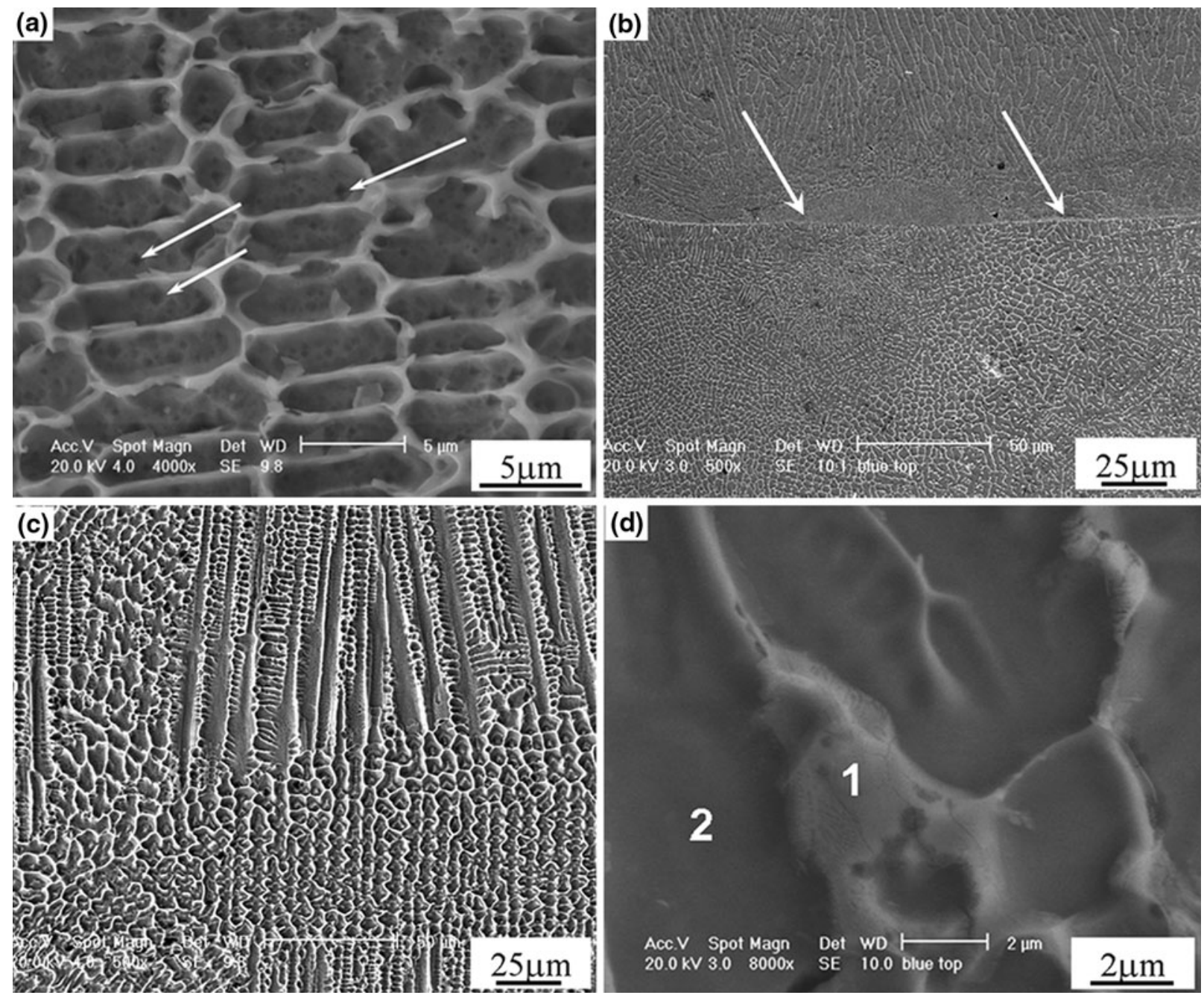

Fig. 1-SEM image of the cross section of coating A: $(a)$ through $(c)$ the middle part and $(d)$ the part near the bonding zone in the first layer.

orientation of the former layer continues epitaxially into the latter deposited one. Figure 1(d) shows the spots taken in EDS in the part near the bonding zone of the first layer of the coating. To be accurate, $\mathrm{C}$ content was not measured. The compositions of spots 1 (interdendrite) and 2 (dendrite) are listed in Table II. According to Figure 1(d) and Table II, there was some Fe in the coating except the part near the bonding zone of the first layer, which indicates the metallurgical bonding with the substrate. During the solidification process, first, $\alpha$-Co dendrites rich in $\mathrm{Co}$ and $\mathrm{Ni}$ formed in the melting pool, and then $\mathrm{W}$ and $\mathrm{Cr}$ were expelled from the dendrites. Therefore, the eutectics were rich in $\mathrm{W}$ and $\mathrm{Cr}$. Because $\mathrm{Co}$ and $\mathrm{Ni}$ have the same face-centered-cubic (fcc) structure and similar atomic radii, a solid solution was easily formed. In addition, Fe contents in the dendrites and eutectics in this part were pretty close.

TEM observations of coating $A$ are shown in Figure 2. Obviously, the dendrite (spot 1 in Figure 2(a), most of it was broken away from the foil during the twin-jet-polishing process) was composed of $\alpha$-Co, and the skeleton structure (spot 2 in Figure 2(c)) in the eutectics was $\mathrm{M}_{23} \mathrm{C}_{6}$. According to the $\mathrm{X}$-ray
Table II. Composition of Spots in Figure 1(d) (Atomic Percent)

\begin{tabular}{lccccc}
\hline Element & Cr & Ni & Co & W & Fe \\
\hline 1 & 14.96 & 17.79 & 49.90 & 0.69 & 16.66 \\
2 & 11.31 & 18.32 & 52.63 & 0.27 & 17.48 \\
\hline
\end{tabular}

microanalysis in STEM, spot 2 was composed of 82 at. pet $\mathrm{Cr}, 11.3$ at. pct $\mathrm{Co}, 1.2$ at. pet Ni, and 5.5 at. pet W. So the $\mathrm{M}_{23} \mathrm{C}_{6}$ carbides were rich in $\mathrm{Cr}$. Moreover, the precipitation of $\mathrm{Co}_{3} \mathrm{~W}$ hard phases was observed in the dendrites (spot 3 in Figure 2(e)), which is in accordance with the tetragonal precipitation in Figure 1(a).

The microstructure of coating B is shown in Figure 3. The composition of spots in Figure 3(b) is shown in Table III. As shown in Figure 3(a), undissolved WC particles (white blocks) distributed randomly in the coating. Dissolution of tungsten carbides depends on the energy applied during laser processing and the dilution with the Fe-based substrate. As the laser moved away, the temperature in the molten pool decreased and large WC particles did not completely melt and were partially 

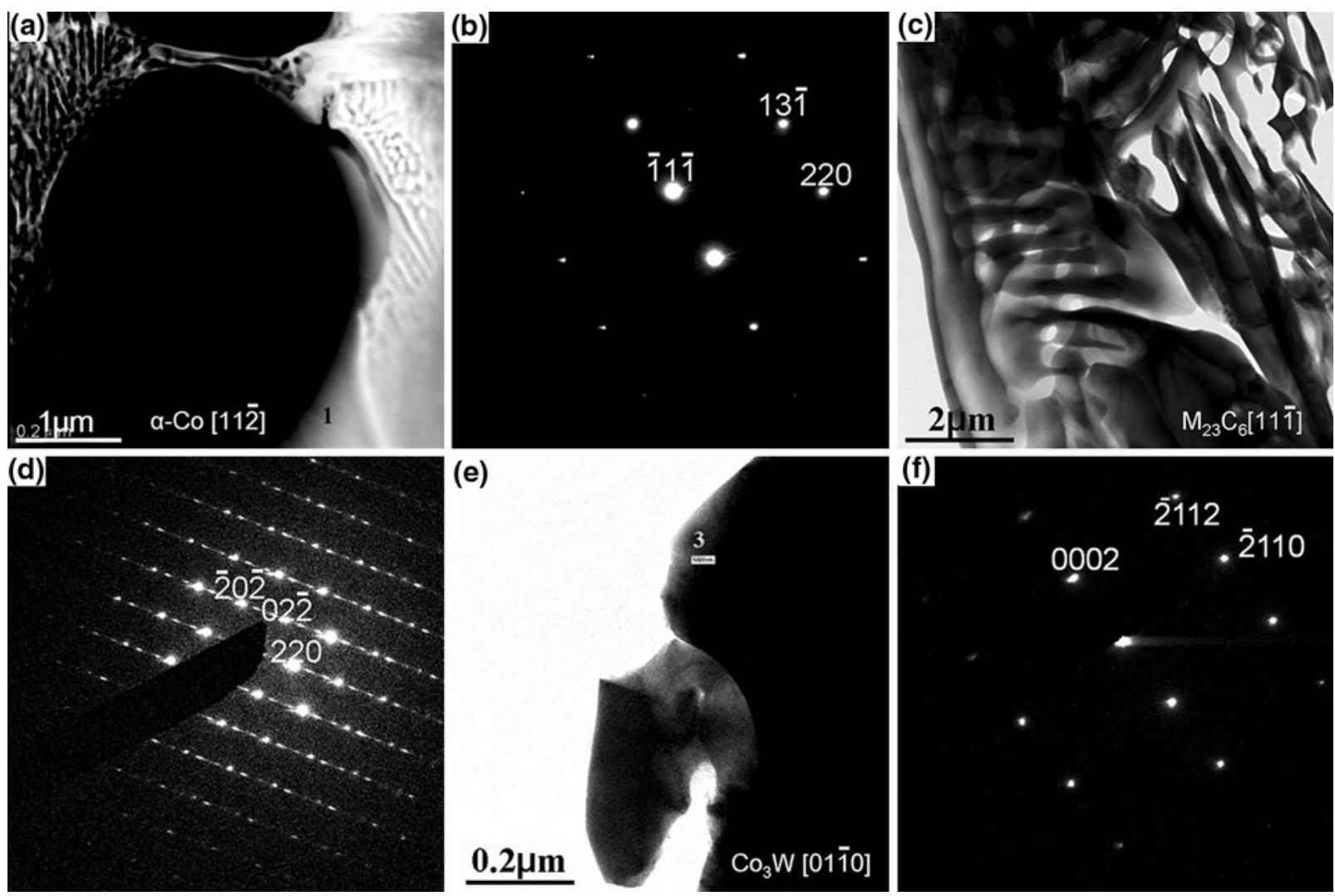

Fig. 2-Bright-field TEM micrographs and their corresponding SAD patterns of coating A: $(b),(d)$, and $(f)$ correspond to spot 1 in $(a)(\alpha-C o)$, spot 2 in $(c)\left(\mathrm{M}_{23} \mathrm{C}_{6}\right)$, and spot 3 in $(e)\left(\mathrm{Co}_{3} \mathrm{~W}\right)$

dissolved and trapped into the Co-285 molten pool. Furthermore, the deposited coating had some micropores in the matrix with $30 \mathrm{wt}$ pct $\mathrm{WC}$ addition. The interface between the undissolved WC and the matrix was adherent and defect free, which is similar to the case in the $\mathrm{MEZ}+\mathrm{Al}+\mathrm{Al}_{2} \mathrm{O}_{3}$ coatings $^{[5]}$ and $\mathrm{MEZ}+\mathrm{SiC}$ coatings. ${ }^{[6]}$ The microstructure in the first layer near the bonding zone was composed of dendrites (spot 1) and eutectics (spot 2 in Figure 3(b)), indicating rapid solidification during the laser processing. Combining Figure 3(b) with Table III, one can see that there was some $\mathrm{Fe}$ in the first layer, indicating the metallurgical bonding between the coating and the substrate. The dendrites were rich in $\mathrm{Ni}, \mathrm{Co}$, and $\mathrm{Fe}$, while the eutectics were rich in $\mathrm{Cr}$ and $\mathrm{W}$. The $\mathrm{Fe}$ content in the first layer in coating $\mathrm{B}$ was higher than that in coating $\mathrm{A}$. The microstructure near the interface between consecutive layers varied with $\mathrm{W}$ and $\mathrm{C}$ content there, as shown in Figures 3(c) and (d). The microstructure in Figure 3(c) was formed where $\mathrm{W}$ and $\mathrm{C}$ content was low in the molten pool, while that in Figure 3(d) was formed where $\mathrm{W}$ and $\mathrm{C}$ content was high. The dendrite structure can hardly be distinguished and the particle size is much smaller in the interface between the two layers (lower part in Figure 3(d)). There is substantial remelting of the underlying layer during the process. Some of the dendrite structure fractured into the molten pool, and fine and dispersive particles formed as the result of the effects of convection and diffusion.
Different morphologies of coating B are shown in Figure 4. In addition to the common dendrites and eutectics, there were two different morphologies in the coating. One was composed of the matrix (3) and the faceted third phases (1 and 2) with various shapes (Figure 4(a)), and the other one was composed of the dendrites, the eutectics, and the third phases with various shapes (Figures 4(b) through (d)). The composition of spots in Figure 4 is listed in Table IV, among which spots 7 and 8 were from the dendrites, 6 and 9 were from the third phases, and 10 was from the eutectics. The composition of spot 5 was the average composition of the rectangular area.

As shown in Figure 4(a), the white blocks (1) with different shapes were surrounded by the gray third phases and some white blocks distributed in the matrix. The EDS analysis results in Table IV indicated that W content in spot 1 was almost 80 at. pct (92.94 wt pct), while that in spot 2 was 46 at. pct and spot 3 was the lowest. All three spots had a high content of W. This can be explained as follows: When the laser passed by, the temperature in the molten pool rose to where higher than the melting point of WC, small WC particles dissolved totally into the Co-285 superalloy pool, while large WC particles dissolved partially. During the fast cooling process, totally and partially dissolved WC particles nucleated heterogeneously and grew preferentially into white blocks. These blocks were surrounded by liquids with a lower W content. Subsequently, the 

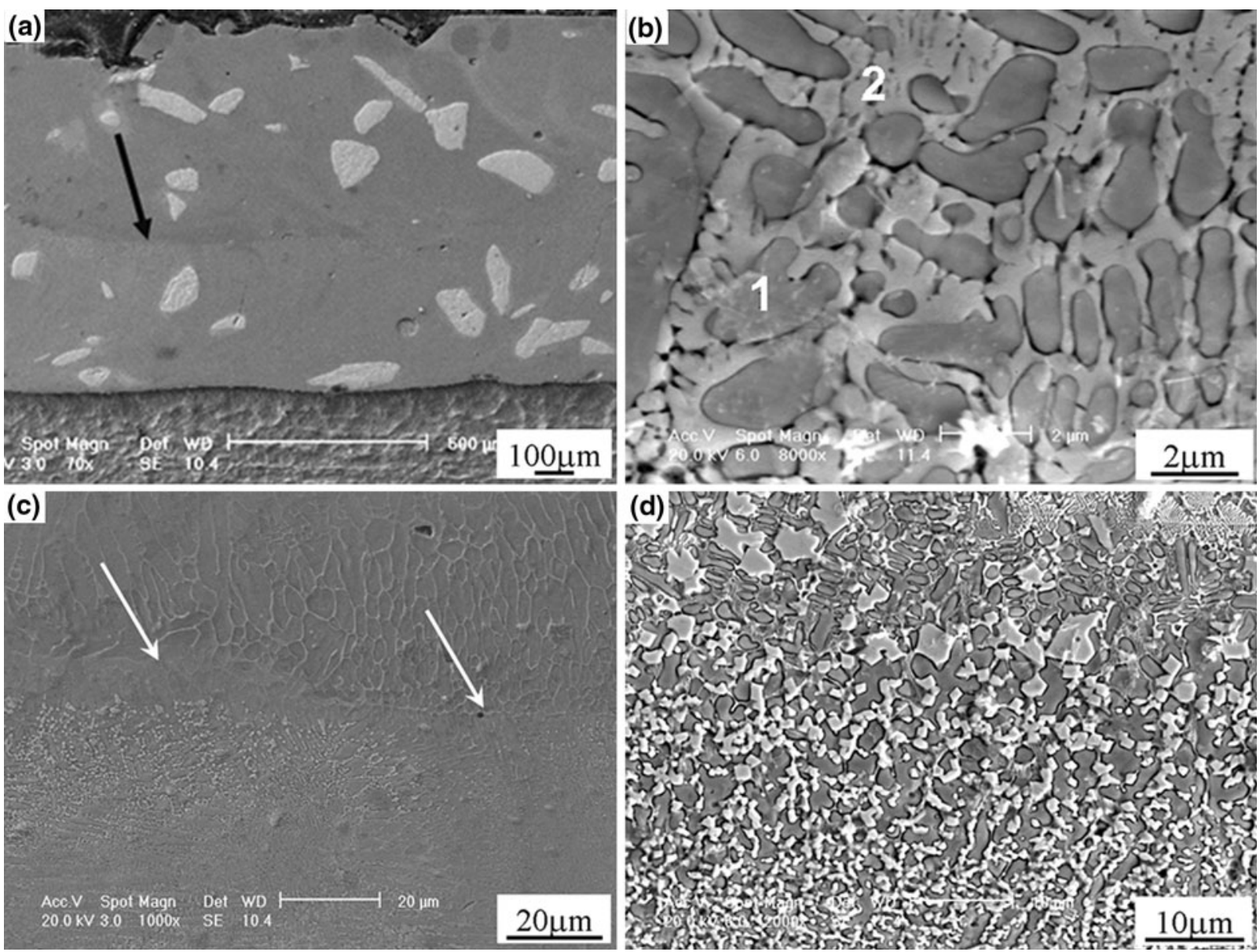

Fig. 3-SEM micrographs showing morphology of $(a)$ the cross section of coating $\mathrm{B},(b)$ the first layer near the bonding zone, and $(c)$ and (d) the interface between two layers in coating B.

Table III. Composition of Spots in Figure 3(b) (Atomic Percent)

\begin{tabular}{lcccrc}
\hline Element & Cr & Ni & Co & W & Fe \\
\hline 1 & 13.52 & 9.2 & 35.99 & 8.58 & 32.71 \\
2 & 21.35 & 5.94 & 28.18 & 19.88 & 24.65 \\
\hline
\end{tabular}

peritectic reaction occurred, resulting in a microstructure with a lower $\mathrm{W}$ and higher $\mathrm{Ni}$ and $\mathrm{Co}$ content, which was similar to the structure in the literature. ${ }^{[19]}$ Due to the fast cooling rate, neither the convection nor the diffusion process was thorough. As a result, the peritectic reaction stopped before it completed. Consequently, the microstructure with white blocks surrounded by the gray third phases whose chemical composition was between WC and Co-285 was formed. Due to the composition fluctuations, the blocks distributed randomly. Some were surrounded by the gray third phases and some were in the matrix.

The second microstructure can be divided into three types according to the shapes of the third phases, marked as A, B, and C in Figures 4(b) through (d). All of them were characterized by dendrites, eutectics, and the third phases. Third phases marked as A were with dendrite and rod shapes, while those marked as B were with block or star shapes and those marked as $\mathrm{C}$ with flower or coral shapes. According to Figure 4 and Table IV, we can see that the dendrites were rich in Co and $\mathrm{Ni}$, while the eutectics were rich in $\mathrm{Cr}$ and $\mathrm{W}$. The eutectics had a higher $\mathrm{Cr}$ content compared with the other two phases. The content of $\mathrm{W}$ in the third phases was higher than that in both the dendrites and the eutectics. Comparing spots 5, 6, and 9, we can see that $\mathrm{W}$ content in these three different shapes from high to low was block or star shapes (6), dendrite or rod shapes (9), and flower or coral shapes (5). Further, the corresponding $\mathrm{W}$ content in them were around 39 at. pct, 30 at. pct, and 19 at. pct, respectively. This phenomenon can be explained by the fact that as the solidification started, the partially dissolved WC particles served as preferential nucleation sites or planes for heterogeneous nucleation, and then crystal nuclei grew epitaxially. They developed into dendrites or blocks according to the direction of the temperature gradient and the original planes. For those totally dissolved WC particles, they just resolidified according to the composition and temperature gradient, resulting in flower- or coral-shaped third phases. Based on the preceding analysis, the solidification process should be described as follows: the Co-rich dendrites first formed from the 

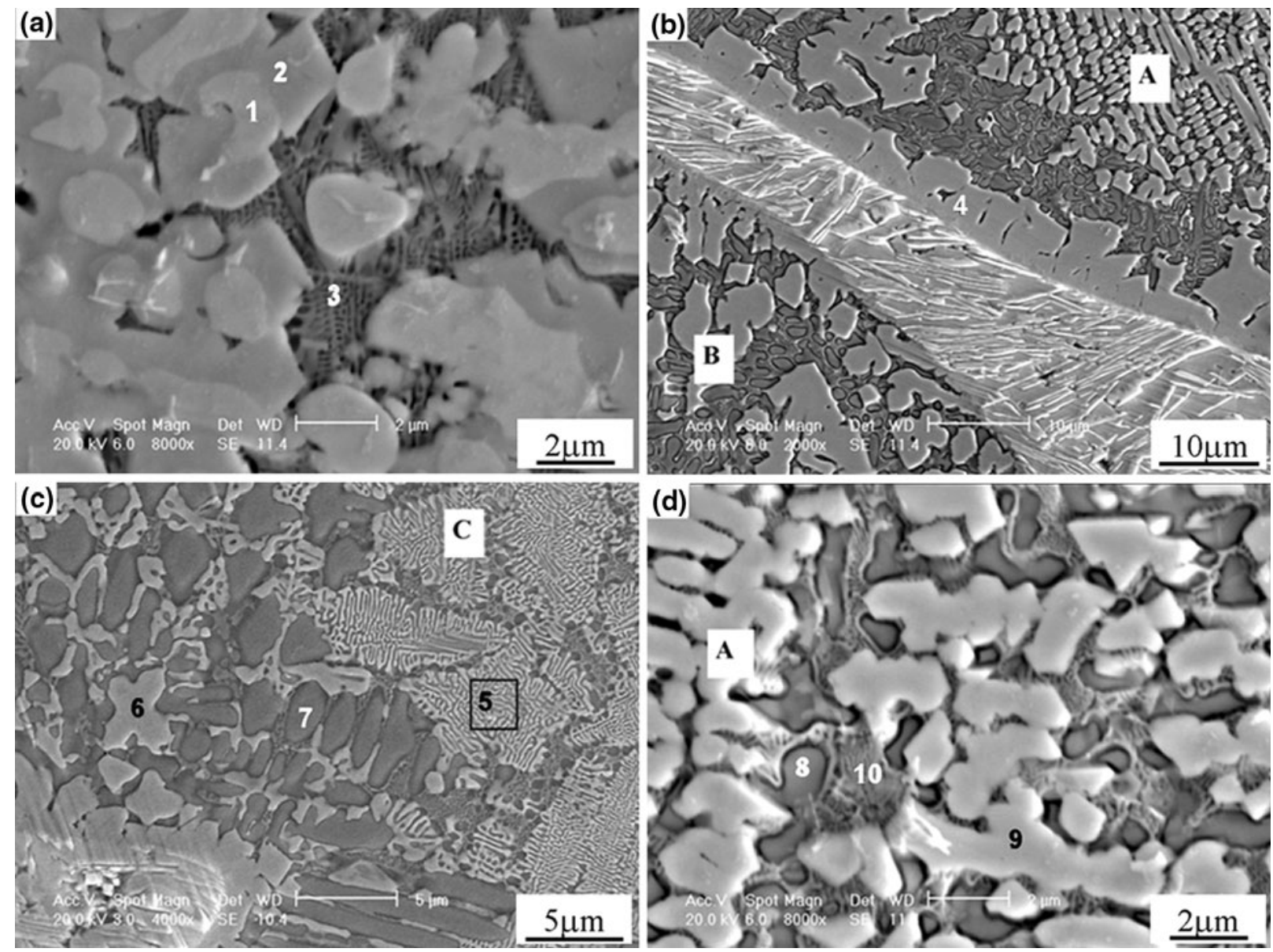

Fig. 4-SEM micrographs showing different morphologies of coating B.

Table IV. Composition of Spots in Figure 4 (Atomic Percent)

\begin{tabular}{llrrr}
\hline Element & $\mathrm{Cr}$ & $\mathrm{Ni}$ & $\mathrm{Co}$ & $\mathrm{W}$ \\
\hline 1 & 14.13 & 0 & 6.37 & 79.5 \\
2 & 15.78 & 3.00 & 35.76 & 45.46 \\
3 & 31.8 & 5.73 & 33.91 & 28.57 \\
4 & 18.1 & 5.88 & 30.27 & 45.75 \\
5 & 24.89 & 10.45 & 46.02 & 18.66 \\
6 & 24.27 & 7.07 & 29.23 & 39.44 \\
7 & 21.51 & 14.38 & 55.56 & 8.54 \\
8 & 30.56 & 6.43 & 37.00 & 26.01 \\
9 & 26.43 & 7.12 & 37.17 & 29.28 \\
10 & 39.12 & 6.88 & 37.09 & 16.91 \\
\hline
\end{tabular}

liquid state. So, $\mathrm{Cr}$ and $\mathrm{W}$ became enriched in the remaining liquid in the interdendrite regions, and a eutectic carbide structure formed. At the same time, the totally and partially dissolved WC solidified in the Co-285 superalloy molten pool. As the temperature gradient, cooling rate, and composition differences varied, the solidification structure changed from area to area, which was typical in fast solidification. According to Si's research ${ }^{[20]}$ on $\mathrm{WC}_{p} / \mathrm{Ni}$ cermet coating, they also obtained the undissolved WC particles and W-rich carbide blocks (similar to B here), but no structure like $\mathrm{C}$ here in the coating. The microstructure of the laser clads of Stellite $12+$ WC was similar to A and B in the Co285 + WC coating, and it varied with different laser energy densities. ${ }^{[21]}$ Zhong's research on laser cladding of Stellite $6+$ WC gave similar structures. ${ }^{[19]}$ According to Table IV, there were some $\mathrm{Co}, \mathrm{Cr}$, and $\mathrm{Ni}$ contents, though $\mathrm{W}$ was the dominant element in the peripheral area of undissolved WC (spot 4), indicating a metallurgical bonding between undissolved $\mathrm{WC}$ and the matrix, where undissolved $\mathrm{WC}$ acts as wear-resistant phases without flaking off the matrix under wear conditions.

Adhesion between the coatings and the substrate is characterized by an interfacial indentation test (load $100 \mathrm{~g}$ ). Figure 5 shows the micrograph relative to this test. No decohesion between the coating and substrate was observed in either of these two cases. Good metallurgical bonding and plastic deformation in the corners of the indentation patterns were observed, especially the indentation on coating $\mathrm{B}$, which was caused by the high hardness of coating $\mathrm{B}$, as shown in Figure 5(b).

The XRD patterns of coatings $\mathrm{A}$ and $\mathrm{B}$ are presented in Figure 6, and the corresponding JCPDS file is shown in Reference 22. As can be seen from Figure 6(a), $\alpha$-Co solid solution, $\mathrm{Cr}_{23} \mathrm{C}_{6}$, and $\mathrm{Co}_{3} \mathrm{~W}$ were formed on 

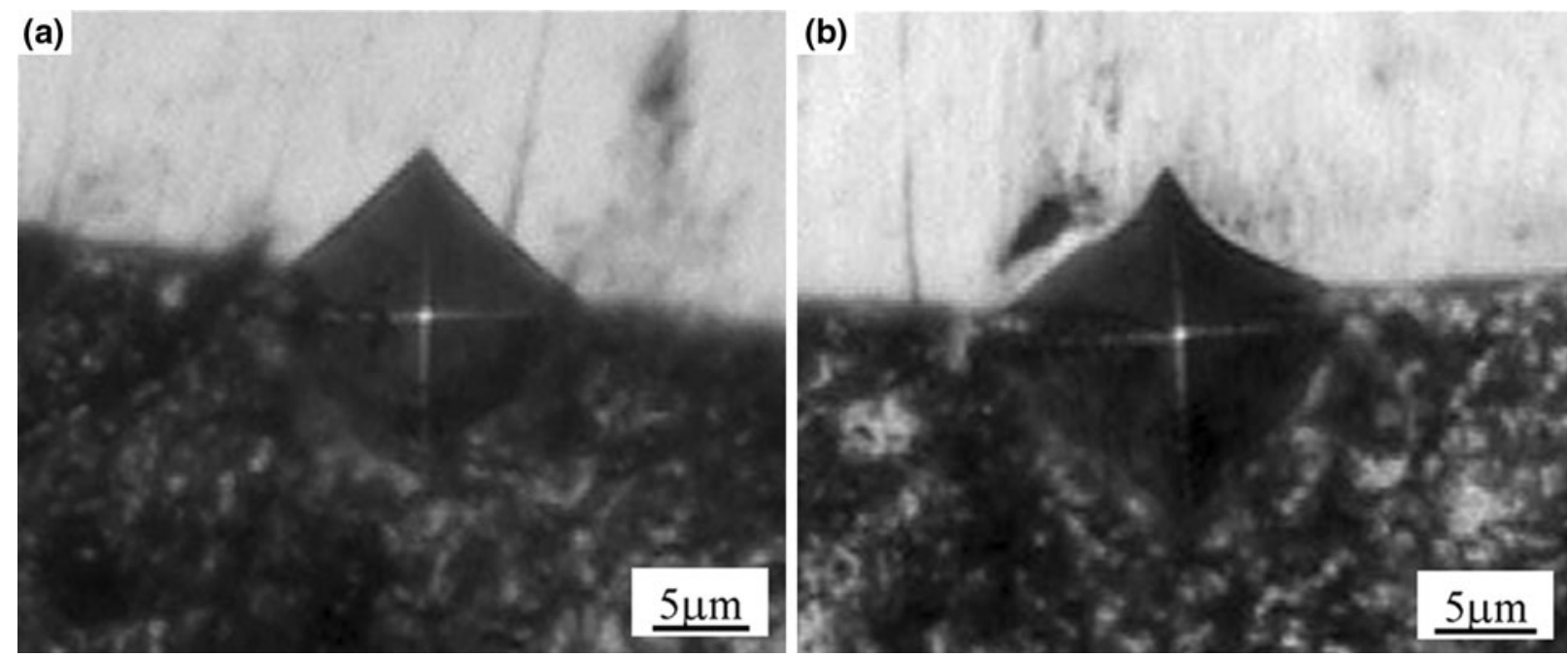

Fig. 5-Micrographs showing indentation on the interface between (a) coating A and the substrate and (b) coating B and the substrate.

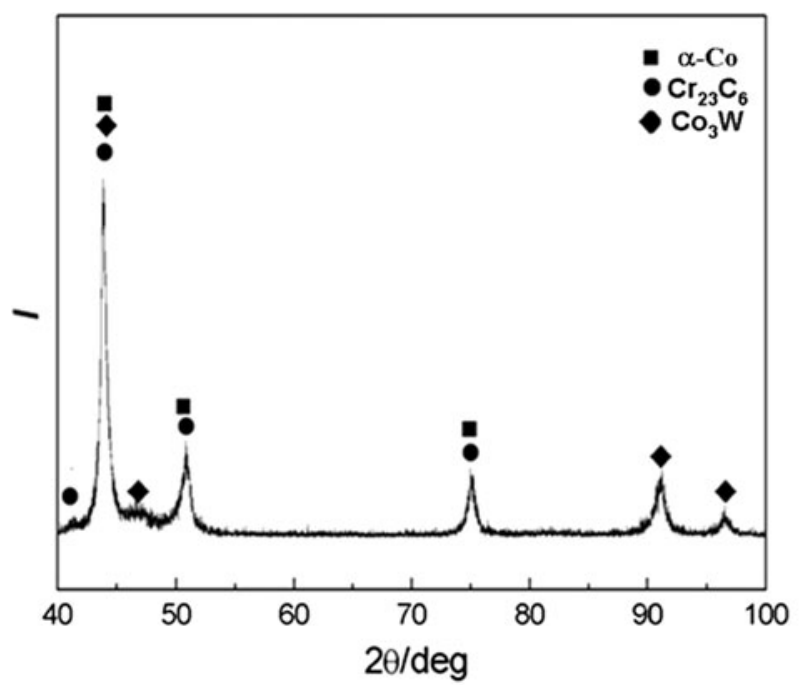

(a)

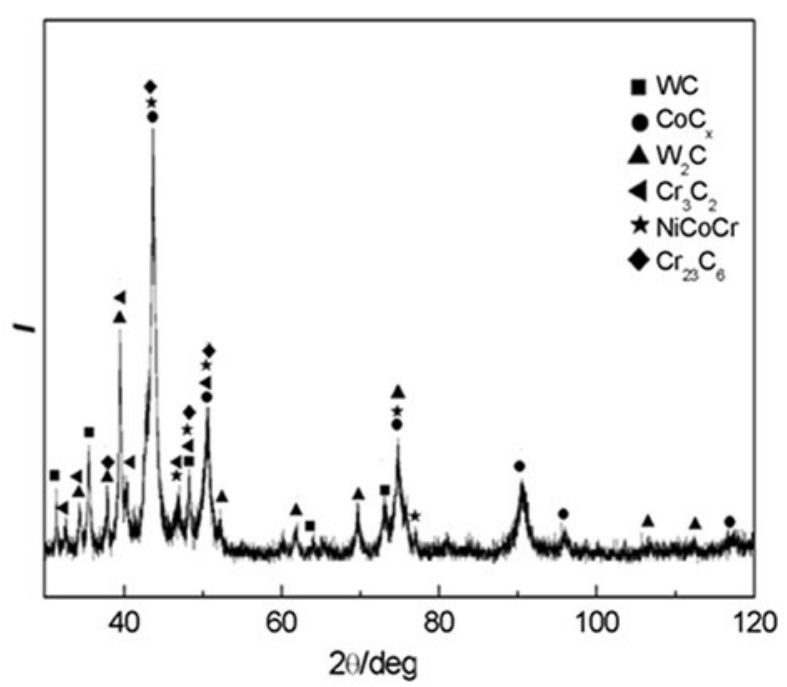

(b)

Fig. 6-XRD pattern showing the surface of $(a)$ coating A and $(b)$ coating B.

coating A. The supersaturated $\alpha$-Co solid solution, which contained $\mathrm{Ni}, \mathrm{Cr}, \mathrm{W}$, and $\mathrm{C}$, first precipitated from the molten pool during solidification. As the temperature approached the eutectic reaction temperature, eutectics formed. According to the $\mathrm{Co}-\mathrm{W}$ binary phase diagram in the ASM Handbooks online, as the temperature decreased to $1093{ }^{\circ} \mathrm{C}, \mathrm{Co}_{3} \mathrm{~W}$ precipitated from the $\alpha$-Co solid solution. Due to the fast solidification rate, the transformation from fcc $\alpha$-Co to hcp $\varepsilon$-Co was restrained, so the room-temperature microstructure was composed of the fcc $\alpha$-Co. Combined with the SEM and TEM results, we can say that the dendrites consisted of $\alpha$-Co with an fcc crystal structure and tetragonal $\mathrm{Co}_{3} \mathrm{~W}$ precipitates were surrounded by a mixture of a Co-rich phase and other $\mathrm{Cr}$-rich $\mathrm{M}_{23} \mathrm{C}_{6}$ carbide phases, resulting from the eutectic reaction that formed interdendrites during solidification.
According to the XRD pattern peaks and their corresponding $\theta$ values, the least-squares fit method was used to calculate the lattice parameters of the $\alpha$-Co solid solution. The calculated value of it was approximately $0.34586 \mathrm{~nm}$, which was slightly smaller than the standard lattice parameter, $0.35441 \mathrm{~nm}$. This result was the co-effect of the compression effects of $\mathrm{Co}_{3} \mathrm{~W}$ and $\mathrm{M}_{23} \mathrm{C}_{6}$, which had larger lattice parameters than the $\alpha-\mathrm{Co}$, and the size effects among the alloying elements that formed into the solid solution.

In addition to unmelted WC, Co-rich solid solution, $\mathrm{W}_{2} \mathrm{C}, \mathrm{CoC}_{x}, \mathrm{Cr}_{3} \mathrm{C}_{2}$, and $\mathrm{Cr}_{23} \mathrm{C}_{6}$ phases were formed in coating B (Figure 6(b)). Because $\mathrm{Co}, \mathrm{Ni}$, and $\mathrm{Cr}$ have a similar atom radius, $\mathrm{NiCoCr}$ solid solution was easily formed over the entire composition during laser processing. As the laser power here was higher than that for coating $\mathrm{A}$, there was more heat input in coating $\mathrm{B}$. 
Furthermore, the heat conductivity of WC is smaller than that of Co-285, so the molten pool in coating B had a long lasting time. Thus, alloying elements had enough time to diffuse and $\mathrm{NiCoCr}$ solid solution instead of $\alpha$-Co solid solution was formed. SEM results show that the dendrites consisted of $\mathrm{NiCoCr}$ solid solution were surrounded by a mixture of the third phases with various shapes and the $\mathrm{NiCoCr}$ solution, $\mathrm{Cr}_{3} \mathrm{C}_{2}$, and $\mathrm{Cr}_{23} \mathrm{C}_{6}$ carbides resulting from the eutectic reaction into interdendrites during solidification. Taking the molten pool as a closed system, as the total energy in the system remains constant, all the reactions tend to increase the entropy and decrease the Gibbs energy. Under nonequilibrium solidification, metastable phases were easily formed as the composition and thermal condition (gradient and cooling rate) vary to a large extent from layer to layer.

According to the $\mathrm{C}-\mathrm{Cr}$ binary phase diagram in $A S M$ Handbook, vol. 03, when the composition of $\mathrm{C}$ is around $13 \mathrm{wt}$ pct and the temperature is around $2084 \pm 10 \mathrm{~K}$ $\left(1811 \pm 10{ }^{\circ} \mathrm{C}\right), \mathrm{Cr}_{3} \mathrm{C}_{2}$ is formed. When the temperature decreases to $1849 \pm 10 \mathrm{~K}\left(1576 \pm 10^{\circ} \mathrm{C}\right)$ and the composition of $\mathrm{C}$ is between 5.5 and $5.8 \mathrm{wt}$ pct, $\mathrm{Cr}_{23} \mathrm{C}_{6}$ is formed. The reactions can be listed as follows:

$$
\begin{gathered}
3 \mathrm{Cr}+2 \mathrm{C} \rightarrow \mathrm{Cr}_{3} \mathrm{C}_{2} \\
23 \mathrm{Cr}+6 \mathrm{C} \rightarrow \mathrm{Cr}_{23} \mathrm{C}_{6}
\end{gathered}
$$

In areas near undissolved $\mathrm{WC}$, where the content of $\mathrm{C}$ was high due to the partial dissolution of $\mathrm{WC}, \mathrm{CoC}_{x}$ metastable phase was formed easily. When the compositions of $\mathrm{C}$ are 6 and 9 wt pct, $\mathrm{Co}_{3} \mathrm{C}$ and $\mathrm{Co}_{2} \mathrm{C}$ metastable phases are formed (C-Co binary phases in $A S M$ Handbook, vol. 03). The reaction is as follows:

$$
\mathrm{Co}+x \mathrm{C} \rightarrow \mathrm{CoC}_{x}
$$

In addition, melted $\mathrm{WC}$ decomposed into $\mathrm{W}$ and $\mathrm{C}$ atoms, which resolidified into $\mathrm{W}_{2} \mathrm{C}$, distributing at the edge of the unmelt WC particles:

$$
\begin{gathered}
\mathrm{WC} \rightarrow \mathrm{W}+\mathrm{C} \\
2 \mathrm{~W}+\mathrm{C} \rightarrow \mathrm{W}_{2} \mathrm{C}
\end{gathered}
$$

These reactions occurred when they satisfy the composition and energy requirements in the entire molten pool.

$\mathrm{W}_{2} \mathrm{C}, \mathrm{Cr}_{23} \mathrm{C}_{6}, \mathrm{Cr}_{3} \mathrm{C}_{2}$, and $\mathrm{CoC}_{\mathrm{x}}$ dispersion hard phases could improve the hardness of the coating significantly. The phases here are slightly different from the ones in References 18 and 19.

\section{B. Crack Behavior in Coating B (Co-285 + 30 Wt Pct $W C$ )}

The morphology of cracks in coating B is shown in Figure 7. As can be seen in Figure 7(a), microcracks existed near the undissolved WC particles. That is the co-effect of the material itself and the stress it bears, which are the two effect factors of cracks. According to the Metals Handbook, 9th ed., the coefficients of thermal expansion of $\mathrm{WC}$ and $\mathrm{Co}$ are $6.2 \times 10^{-6} \mu \mathrm{m} / \mathrm{K}$ and $13.8 \times 10^{-6} \mu \mathrm{m} / \mathrm{K}$, respectively. During the process of fast heating and cooling of laser, large thermal stress arose between the interface of undissolved $\mathrm{WC}$ and the matrix, whose coefficients of thermal expansion differed. As a result, cracks initiated near the interface between them.

As for the matrix of the Co-285, cracks existed and propagated in the eutectics (Figure 7(b)). They can be divided into transgranular cracks and intergranular cracks, which are the typical solidification cracks. This phenomenon can be explained by the fact that there is composition fluctuation in the molten pool caused by
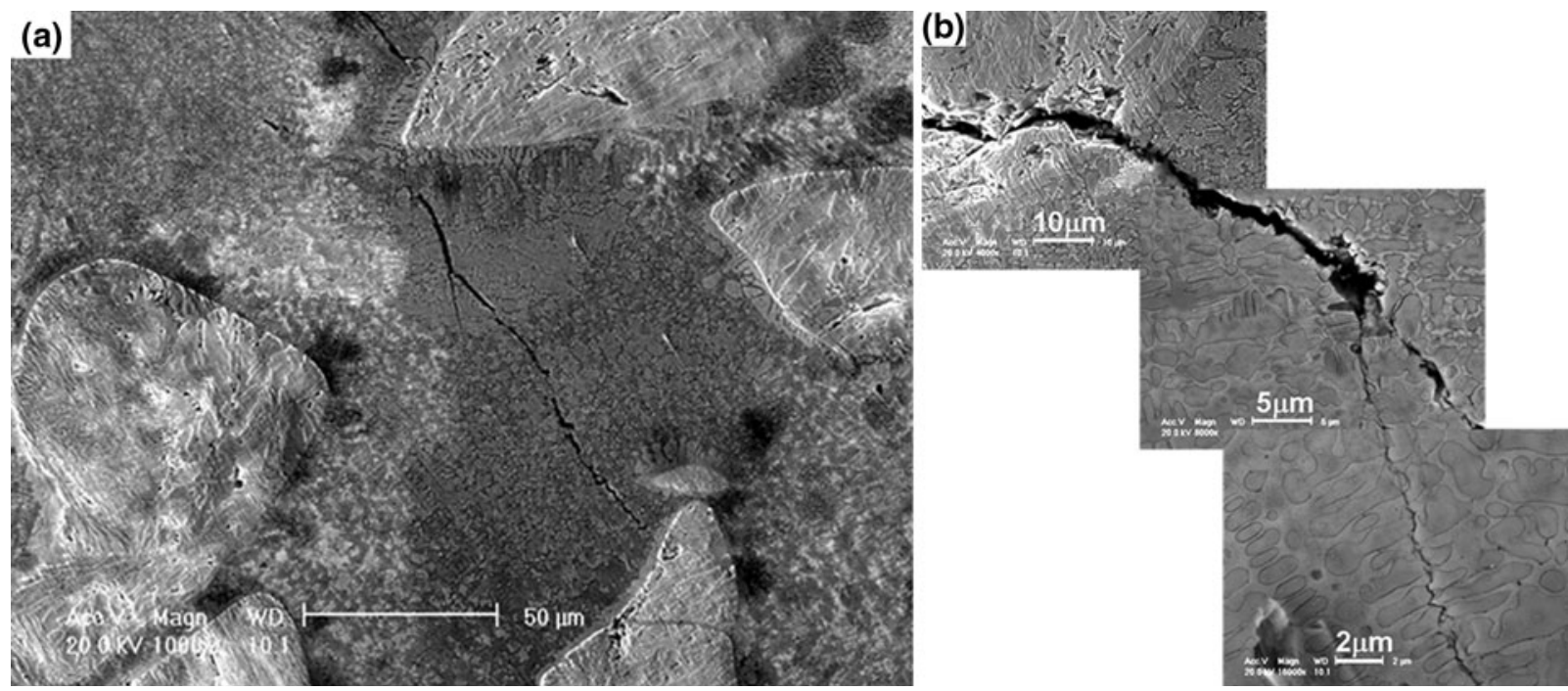

Fig.7-Morphology of cracks in coating B. 
the fast cooling rate of laser. As a result, the composition in one grain is not even. When the temperature decreases to the melting point, those elements with high melting points solidify first, resulting in the enrichment of low-melting elements and a liquid film around the grain boundary. Furthermore, pores and defects enrich at grain boundaries. Consequently, when shrinking tensile stress is higher than the interfacial tension of the liquid film, cracks initiate and propagate along the grain boundaries. In the case of small stress, cracks distribute along dendrites and propagate along the crystalline direction in laser cladding layers. Even if the cracks do not propagate parallel to the crystalline direction, they will adjust to it. However, in the case of large stress and cracks propagating normal to the crystalline direction, cracks will break through dendrites and propagate along their original direction, generating intergranular cracks. The lowest picture in Figure 7(b) shows the intergranular cracks in the deposited coating, indicating the large stress in the coating. The stresses on the matrix around undissolved WC were radial tensile stress and compressive hoop stress, which were the result of the differences between the Young's modulus of WC $(708 \mathrm{GPa})$ and Co-285 (210 GPa) as well as the differences between their coefficients of thermal expansion. When cracks approached undissolved WC particles, instead of propagating directly to the undissolved $\mathrm{WC}$, they changed their directions to be parallel to the direction of hoop stress and perpendicular to the direction of radial stress. That is to say that, when cracks approached undissolved WC, they deflexed to the undissolved WC, arrived at the interface between them, and then propagated along their original directions.

\section{Hardness Distribution}

The variations of microhardness along the depth of coatings $\mathrm{A}$ and $\mathrm{B}$ are given in Figure 8 . It is necessary to mention that the average thicknesses of each layer of coatings $\mathrm{A}$ and $\mathrm{B}$ are 1.1 and $0.65 \mathrm{~mm}$, respectively. The hardness fluctuated throughout the layer in coating A,

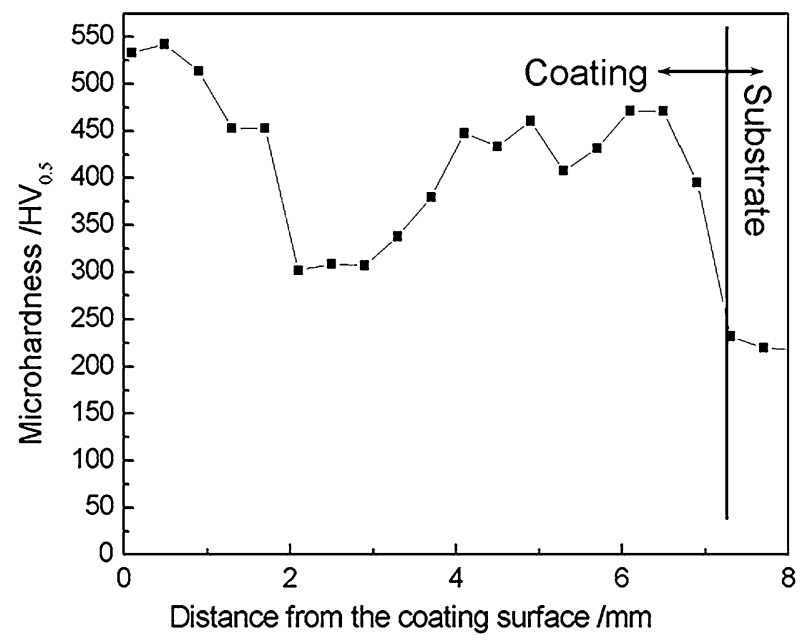

(a) which is in accordance with the composition fluctuation. There was a microhardness descent at the depth of 2 to $3 \mathrm{~mm}$ to the surface of the coating, which was the result of the poor bonding between the second and third layers and the poor quality of the third layer (micropores in Figure 1(b)). Additionally, the average hardness value of $420 \mathrm{HV}$ was achieved for the Co-285 layer, which may be mainly attributed to the formation of $\mathrm{M}_{23} \mathrm{C}_{6}$ and $\mathrm{Co}_{3} \mathrm{~W}$ hard phases in the coating as well as the solid solution strengthening in the supersaturated $\alpha$-Co solid solution. The dendrites were not as hard as eutectics, which consisted of hard phases. The microhardness of the coating was not improved too much due to the large amount of the $\alpha$-Co dendrites (73 pct).

The hardness distribution varied a little throughout coating B (Figure 8(b)). Furthermore, the microhardness increased in the first layer near the bonding zone, which could be partially due to the dilution of the base material $\mathrm{Fe}$ and the intermixing of the Co-285 + WC with Fe and partially due the high quenching rate from the underlying substrate. The former reason is in good agreement with the chemical composition in this area (Table III), and the latter one is in good accordance with the results from Majumdar. ${ }^{\text {[23] }}$ As $\mathrm{Fe}, \mathrm{Ni}$, and $\mathrm{Co}$ have similar atom radii, one can substitute another to form the substitution solid solution, resulting in the increase of microhardness in the first layer near the bonding zone. Additionally, the average hardness value of $751 \mathrm{HV}$ was achieved for the matrix in Co-285 + WC coating, which was almost 1.8 times that of the Co-285 coating (420 HV). This was mainly attributed to the formation of hard phases, such as $\mathrm{W}_{2} \mathrm{C}, \mathrm{Cr}_{23} \mathrm{C}_{6}, \mathrm{Cr}_{3} \mathrm{C}_{2}$, and $\mathrm{CoC}_{x}$ in coating $\mathrm{B}$ as well as the solid solution strengthening in the supersaturated $\mathrm{NiCoCr}$ solid solution.

\section{Wear Behavior}

Compared with coating A, the wear volume loss of coating B was much less, as shown in Figure 9. The volume loss for coating A was 2.4 times that of coating

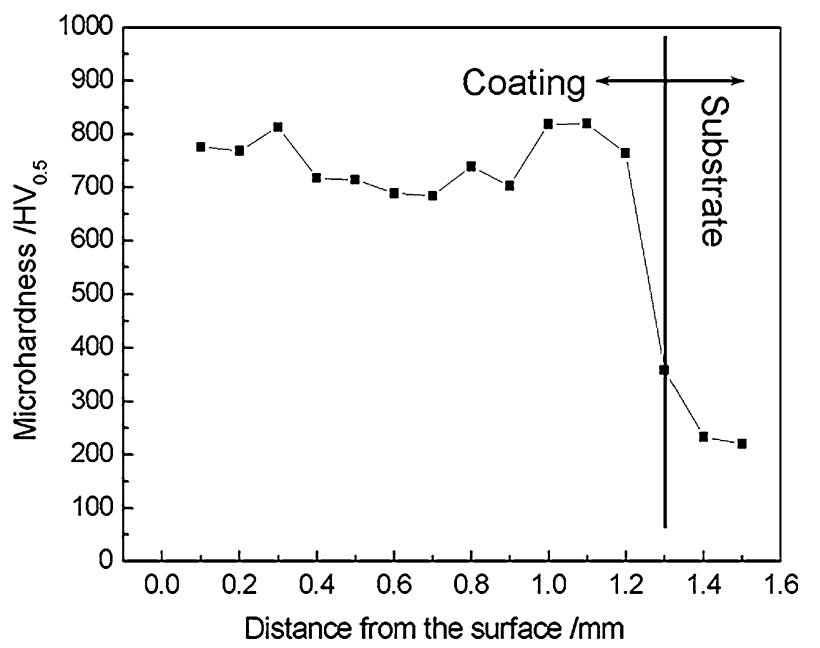

(b)

Fig. 8-Microhardness distribution along the depth of $(a)$ coating A and $(b)$ coating B. 
$\mathrm{B}$ at the wear time of 10 minutes, and this ratio rose to 7.8 at 60 minutes. Thus, the addition of $\mathrm{WC}$ to the Co-285 coating can significantly improve the wear resistance of Co-285. After the first 10 minutes, the

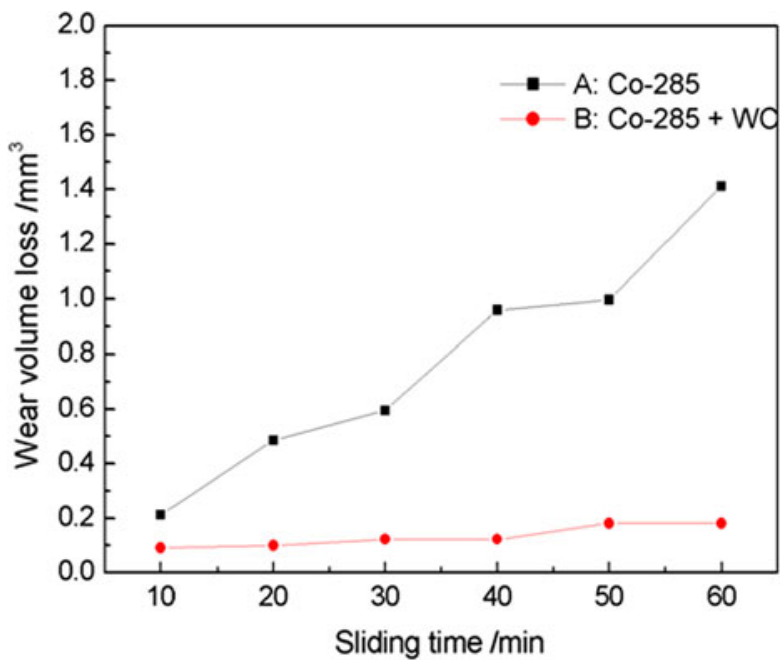

Fig. 9-Volume losses against sliding time in wear tests for coatings $\mathrm{A}$ and $\mathrm{B}$. wear volume loss increased significantly for coating A, while in the case of coating $\mathrm{B}$, the total wear stayed almost the same. For coating $B$, it was only after 40 minutes that the wear volume increased a little. The wear volume loss of the Co-285 coating after 60 minutes $(420 \mathrm{~m})$ wear test was about $1.4 \mathrm{~mm}^{3}$, and that of Co-285 + WC was $0.18 \mathrm{~mm}^{3}$.

As can be seen in Figure 10(a), platelike debris were pulled out from the seriously worn surface of coating A, which indicated a typical adhesive wear mechanism. Also, the wear grooves indicated an abrasive wear, in which debris served as wear particles. In abrasive wear, a surface is in sliding contact with hard particles or hard protuberances on a counterface. Provided that the surface is not too brittle (cobalt-based alloys have good plasticity), when the contact pressure between the surface and a harder sliding three-dimensional asperity exceeds the elastic limit of the surface, material plastically displaced on the surface is pushed sideways, and sometimes upward, along the asperity (Figure 10(a)). The sideways-flowing material formed side ridges on the worn groove microploughing, and the upward-flowing material formed chips that left the surface microcutting. Whether and how much of the plastically displaced material became microcutting chips depended mainly on the asperity geometry, the strain hardening ability of the
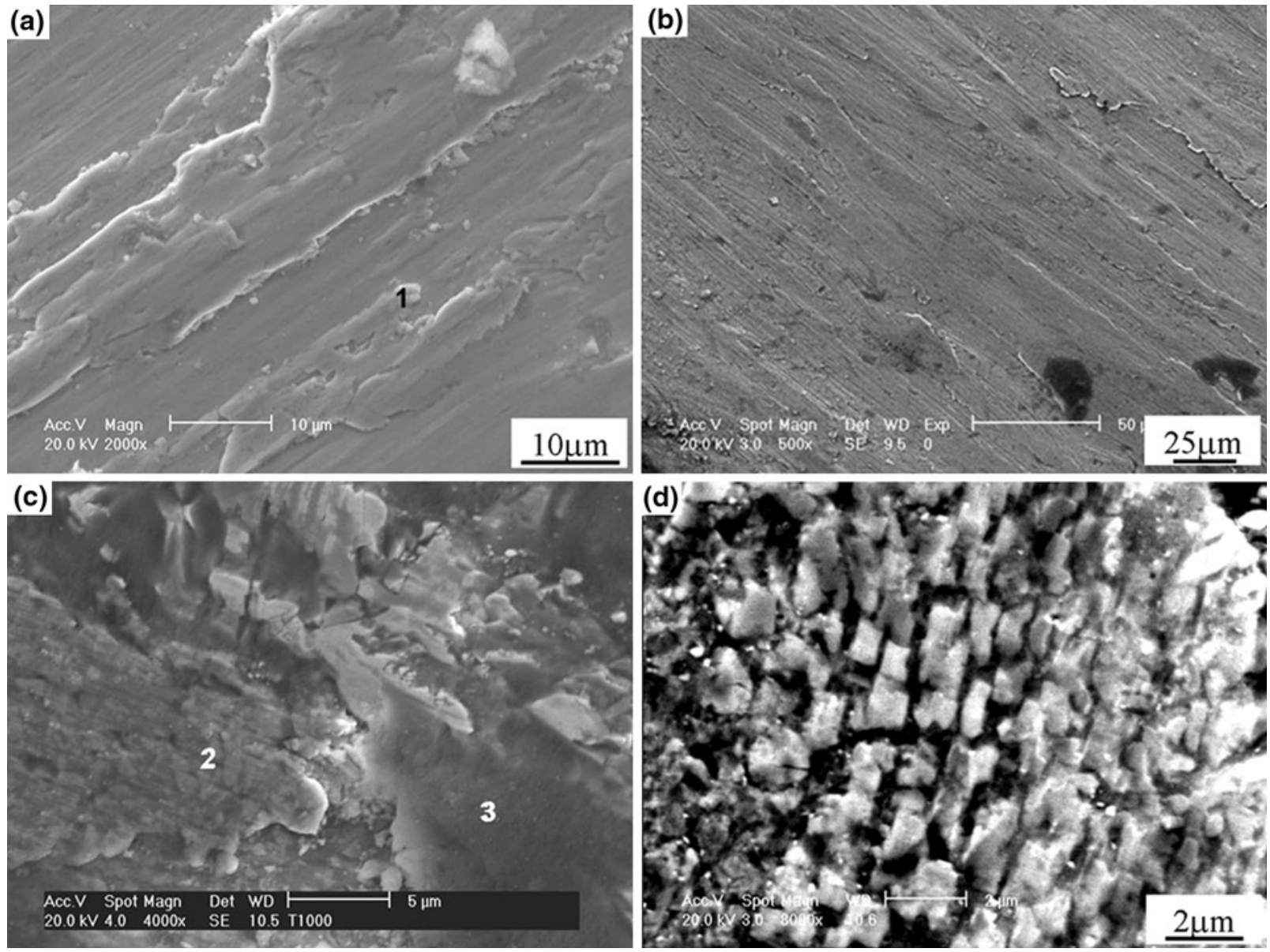

Fig. 10 - SEM morphologies showing the worn surface of $(a)$ coating A and $(b)$ through $(d)$ coating B after a 60 min wear test. 
Table V. Chemical Composition of Spots in Figure 10 (Atomic Percent)

\begin{tabular}{lcrc}
\hline Element & 1 & 2 & 3 \\
\hline $\mathrm{Cr}$ & 24 & 18.26 & 5.55 \\
$\mathrm{Ni}$ & 9.78 & 10.43 & 2.24 \\
$\mathrm{~W}$ & 2.8 & 6.82 & 8.12 \\
$\mathrm{Co}$ & 43.72 & 39.16 & 9.13 \\
$\mathrm{O}$ & 19.7 & 20.97 & 58.97 \\
$\mathrm{Al}$ & 0 & 4.36 & 15.99 \\
\hline
\end{tabular}

surface, and the interfacial friction. According to the EDX analysis (Table V), Co, $\mathrm{Cr}, \mathrm{Ni}, \mathrm{W}$, and $\mathrm{O}$ existed in the debris (spot 1) on the worn surface of coating A, which indicated that oxidation wear also occurred here. There was no Al on the worn surface, suggesting the material transfer in the adhesive wear must be from coating A to the ruby ball.

In contrast, the worn surface of coating B appeared smoother, indicating improved adhesive wear, as shown in Figure 10(b). While there were also wear grooves on the wear surface, the groove volume was much smaller than that of coating $\mathrm{A}$, indicating improved abrasive wear resistance. The predominant wear mechanism was mainly an abrasive sliding process of metallic matrix and tungsten carbides. Figure 10(c) shows the morphology close to undissolved WC, and no failure of the interface between tungsten carbide and the matrix could be observed. So, the undissolved WC particles, which had a high hardness in the coating, could resist the microplowing. EDX analysis of spots 2 and 3 on the undissolved $\mathrm{WC}$ in Figure 10(c) indicated $\mathrm{Co}, \mathrm{Cr}$, Ni, $\mathrm{W}, \mathrm{O}$, and $\mathrm{Al}$ existed on the worn surface of coating $\mathrm{B}$, suggesting oxidation wear and material transfer from the ball to coating B. In adhesive wear, if the shear strength of the contacting area is between those of the two contacting materials, the material will be easily transferred from the soft one to the hard one. As the hardnesses of WC and ruby ball are $2265 \mathrm{HV}$ and 1570 to $1800 \mathrm{HV}$, respectively, $\mathrm{Al}_{2} \mathrm{O}_{3}$ was transferred to the undissolved WC. This transformation could reduce the wear loss volume, which was also found in laser-clad 316L stainless steel $+\mathrm{SiC}$ layer. ${ }^{[24]}$ The Al content was much higher in spot 3 than that in spot 2, as could be expected from the color of these spots. The dark material on the undissolved WC must be the transferred ball material. It seemed that the dark area had a high contact pressure with the counterface ball, while the gray area had a relatively low one. That is because the undissolved WC particles, which had a pretty high hardness in the coating, could resist the microplowing. On the other hand, the microstructure of coating B contained a huge content of finely and uniformly distributed reprecipitated secondary carbides $\left(\mathrm{Cr}_{23} \mathrm{C}_{6}\right.$, $\mathrm{CoC}_{x}, \mathrm{Cr}_{3} \mathrm{C}_{2}$, and $\mathrm{W}_{2} \mathrm{C}$ in Figure $10(\mathrm{~d})$ ), which were tightly bound to the metal matrix and remained effective in resisting wear, showing a positive effect on wear resistance, indicating that the matrix of Co-285 superalloy obviously offered enough strength and toughness and gave a good embedding of the hard phases. From the preceding discussion, we can conclude that the undissolved WC and other fine hard carbides could alleviate the sliding against the matrix material as protuberances. At the same time, transferred ball material was trapped in the concaves between the protuberances. Thus, the higher abrasive wear resistance of coating B compared to coating A could be attributed to the high content of hard and wear-resistant WC and other fine carbides, and the tough metal matrix.

\section{CONCLUSIONS}

This article focuses on the evolution of microstructure, phase transformation, and wear behavior in the Co-285 and Co-285 + WC coatings fabricated by laseraided direct metal deposition. Both of the coatings had dense structures, as well as a metallurgical bonding with the steel substrate. In addition, Co-285 + WC coating had some randomly distributed unmelted WC particles in it. XRD analysis indicated the existence of $\alpha$-Co solid solution, $\mathrm{M}_{23} \mathrm{C}_{6}$ type carbides, and $\mathrm{Co}_{3} \mathrm{~W}$ in Co-285 coating and $\mathrm{WC}, \mathrm{NiCoCr}$ solid solution, $\mathrm{W}_{2} \mathrm{C}, \mathrm{CoC}_{x}$, $\mathrm{Cr}_{3} \mathrm{C}_{2}$, and $\mathrm{M}_{23} \mathrm{C}_{6}$ type carbides in $\mathrm{Co}-285+\mathrm{WC}$ coating. The average microhardness of the matrix in coating B was $751 \mathrm{HV}_{0.5}$, which was almost 1.8 times that in coating $\mathrm{A}\left(420 \mathrm{HV}_{0.5}\right)$. Wear results indicated that the wear resistance of coating $\mathrm{B}$ was almost 7.8 times that of coating A after 60 minutes sliding wear test at ambient room temperature. The improvement in wear resistance of coating $\mathrm{B}$ is believed to be partially due to the undissolved $\mathrm{WC}$ and the formation of large numbers of carbides in the matrix working as wear-resistant phases and partially due to the good bonding between the hard phases and the tough matrix.

\section{ACKNOWLEDGMENTS}

This work was made possible by the financial support from the Chinese government. Laser-aided direct metal deposition experiments were performed at the NSF I/UCR Centre for Lasers and Plasmas in Advanced Manufacturing at the University of Michigan (Ann Arbor, MI). The wear test was carried out at the POM Group Inc. (Auburn Hills, MI). Thanks are also due to Cunshan Wang and Kai Sun for their helpful discussions and Dr. Bhaskar Dutta (POM Group) for the wear tests. The studies involving electron microscopy were performed in the Electron Microbeam Analysis Laboratory (EMAL) of the University of Michigan.

\section{REFERENCES}

1. Y. Fujii and K. Maeda: Wear, 2002, vol. 252, pp. 787-98.

2. O.P. Datsyshyn and M.M. Kopylets: Mater. Sci., 2003, vol. 39, pp. 765-79.

3. W.H. Jiang, H.R. Guan, and Z.Q. Hu: Metall. Mater. Trans. A, 1999, vol. 30A, pp. 2251-54.

4. V. Kuzucu, M. Ceylan, H. Çelik, and I. Aksoy: J. Mater. Process. Technol., 1998, vol. 74, pp. 137-41.

5. J.D. Majumder, B.R. Chandra, B.L. Mordike, R. Galun, and I. Manna: Surf. Coat. Technol., 2004, vol. 179, pp. 297-305. 
6. J.D. Majumder, B.R. Chandra, R. Galun, B.L. Mordike, and I. Manna: Compd. Sci. Technol., 2003, vol. 63, pp. 771-78.

7. K.H. Lo, C.T. Kwok, F.T. Cheng, and H.C. Man: J. Laser Appl., 2003, vol. 5, pp. 107-14.

8. F.T. Cheng, C.T. Kwok, and H.C. Man: Mater. Lett., 2002, vol. 57, pp. 969-74.

9. T.L. Li, Q.H. Lou, J.X. Dong, Y.R. Wei, J. Zhou, J.R. Liu, Z.M. Zhang, and F.H. Sun: Appl. Surf. Sci., 2002, vol. 193, pp. 102-19.

10. I. Smurov: Surf. Coat. Technol., 2008, vol. 202, pp. 4496-4502.

11. J. Mazumder, A. Schifferer, and J. Choi: Mater. Res. Innov., 1999, vol. 3, pp. 118-31.

12. A.J. Pinkerton and L. Li: J. Mech. Eng. Sci., 2004, vol. 218, pp. $531-41$.

13. J. Choi and Y. Chang: Int. J. Mach. Tools Manufact., 2005, vol. 45 , pp. 597-607.

14. W.R. Morrow, H. Qi, I. Kim, J. Mazumder, and S.J. Skerlos: J. Clean. Prod., 2007, vol. 15, pp. 932-43.

15. K. Zhang, W.J. Liu, and X.F. Shang: Mater. Sci. Forum, 2007, vols. $534-536$, pp. $457-60$

16. J. Mazumder and H. Qi: Proc. SPIE, 2005, vol. 5706, pp. $38-59$.

17. X. He and J. Mazumder: J. Appl. Phys., 2007, vol. 101, pp. 53113-1-53113-9.

18. J.D. Majumder, A. Pinkerton, Z. Liu, I. Manna, and L. Li: Appl. Surf. Sci., 2005, vol. 247, pp. 320-27.
19. M.L. Zhong, W.J. Liu, K.F. Yao, J.C. Goussain, C. Mayer, and A. Becker: Surf. Coat. Technol., 2002, vol. 157, pp. 128-37.

20. S.H. Si, X.M. Yuan, Y.L. Liu, Y.Z. He, and K. Shin: J. Iron Steel Res. Int., 2006, vol. 13, pp. 74-78.

21. K.A. Chiang and Y.C. Chen: J. Mater. Process. Technol., 2007, vol. 182, pp. 297-302.

22. PDF cards: Coating A: Co 01-089-4307 (E.A. Owen and D. Madoc-Jones: Proc. Phys. Soc., London, 1954, vol. 67, p. 459), $\mathrm{Cr}_{23} \mathrm{C}_{6}$ 00-035-0783 (A. Westgren: Jernkontorets Ann., 1933, vol. 17, p. 501), and $\mathrm{Co}_{3} \mathrm{~W}$ 03-065-3520 (M.M. Babich, E.N. Kisljakova, and J.S. Umanskii: Z. Tekh. Fiz., 1938, vol. 8, p. 119); and Coating B: $\mathrm{Cr}_{23} \mathrm{C}_{6}$ 03-065-3132 (A. Westgren: Jernkontorets Ann., 1933, vol. 117, p. 501), WC 01-073-0471 (A.E. Metcalfe: J. Inst. Met., 1947, vol. 73, p. 591), $\mathrm{CoC}_{x}$ 00-044-0962 (A. Badzian and A. Klokocki: J. Cryst. Growth, 1981, vol. 52, p. 843), $\mathrm{Cr}_{3} \mathrm{C}_{2}$ 01-089-2723 (D. Meinhardt and O. Krisement: Arch. Eisenhuettenwes., 1962, vol. 33, p. 493), $\mathrm{W}_{2} \mathrm{C}$ 00-020-1315 (Rudy St. Windisch: J. Am. Ceram. Soc., 1967, vol. 50, p. 272), and NiCoCr 00-021-1271 (Mihalison et al., Trans. Am. Inst. Min. Eng., 1968, vol. 242, p. 2399).

23. J.D. Majumder, A. Pinkerton, Z. Liu, I. Manna, and L. Li: Appl. Surf. Sci., 2005, vol. 247, pp. 373-77.

24. J.D. Majumder, A. Kumar, and L. Li: Tribo. Int., 2009, vol. 42, pp. $750-53$. 